\title{
Does Mind Mapping Technique Improve Cohesion and Coherence in Composition Writing? An Experimental Study
}

\author{
Muhammad Naqeeb ul Khalil Shaheen ${ }^{*}$ \\ Nazir Haider Shah ${ }^{* *}$ \\ Hajira Naqeeb ${ }^{* * *}$
}

\begin{abstract}
The purpose of this study was to compare the effectiveness of teaching technique based on mind mapping to improve cohesion and coherence in tenth grade students' composition writing. The study used a pre-test and post-test control group design. Sixty (60) junior high school students (30 boys and 30 girls) from two schools were randomly selected. The students in the control group were guided by traditional teaching technique, and the students in the experimental group were guided by mind mapping technique. A Subject Achievement Test (SAT) was used before and after treatment as pre and post tests to collect numerical data. Both inferential and descriptive statistics techniques were used to analyse the data. It was found that in terms of students' SAT, there was a significant difference in the average post-test scores between the experimental group and the control group. In addition, gender has a great influence on students' composition writing. It was concluded that in terms of students' achievements in composition writing, mind mapping technique was more effective than traditional technique. The research may pave the way for future researchers.
\end{abstract}

Keywords: mind-mapping technique, composition writing, grammar translation method, subject achievement test, students' achievement

\footnotetext{
* $\quad$ Lecturer, Department of Education, University of Kotli, AJ\&K

** Assistant Professor, Department of Education University of Kotli, AJ\&K, Email: nazishah786@gmail.com

** $\quad$ Federal Government Education Institution C/G
} 


\section{Introduction}

The successful survival of mankind on Earth depends to a large extent on effective communication and collaboration and the language helps to reach the main objective. Thus, written language can be welldefined as a system created on symbols (sometimes referred to as vocabulary) and grammar (rule sets) that determine the manipulation of symbols in an appropriate manner (Harmer, 2001). Then, depending on the function, the language is a fusion of the two. This communication process includes a unique pattern of sounds or gestures for a particular symbol. There are hundreds of thousands of languages, all of which are common in nature, but the exceptions are obvious (Novak, 2002).

In the early stages of life, you can quickly observe the process of learning a language. For example, without any struggle and conscious effort individuals learn characteristics of their language by their mother tongue (Cavallo, 1996; BouJaoude, 1992). In the learning process lateralization of the brain is taken as a barrier to the rapid development (Novak, 2002). Therefore, it is difficult for learners to be aware, absorb, recall and use the new model accordingly when it comes to the problem of learning a language from a second language. Language is the outcome of four proficiencies: listening, speaking, reading, and writing. Nevertheless, listening and speaking are at a higher level due to their common use in common discussion and reading and writing are considered to be limited to learn discourse, but mastering the focus language requires mastering all four abilities (Taber, 2001; Costa et al., 2000). Indeed, language is a fusion of all these aspects. All aspects of learning a language are associated with the flourishing of any field of knowledge. In fact, the Qur'an describes all the steps involved in acquiring knowledge as follows: "Read. Read the name of your Lord Creator (man). Who is creating humans with blood clots. Reading and your Lord are the most powerful. Who? Know with a pen (man) that he does not know" (Sura-e-Alaq. Sections 1-5).

The verses quoted above also reinforce the same concept. But in fact, it is difficult for learners to master in production of speaking and writing abilities of the language. It is considered to be very problematic because it has the real performance of the learnt language in the case of L1 and the learning in the case of L2. Consequently, the main focus of language teachers throughout the school and university is to enable their students to write a cohesive and coherent writing (Taber, 2001; Costa et al., 2000). When students are required to prepare assignments (such as essay and story writing), they find that using accurate language to produce materials is inefficient. However, students may be able to 
complete assigned tasks, but teachers need to consider students issues and properly resolve them, because good writers are critical to their success in their later years. Francis Bacon correctly said: "Reading makes a person full; meeting makes a prepared person; and writing makes a definite person." Hence, teaching of writing skills has been considered an important aspect while teaching a foreign language.

\section{Background of the Study}

Among the four language skills, writing skill is a skill which is tested in the final assessment of the students at secondary school level in Pakistan. Therefore, it can be assumed that writing skills are one of the most important skills in English teaching in Pakistan. In addition, writing is also very important because it can accelerate the process of students learning the target language (Byrne, 1997).

Information technology has made the world a global village by rapid development due to this English has reached to the status of "universal language". The skills play a decisive role in the interaction and corporate world at the global level therefore writing is one of the vital modes of conveying information. Responsibility lies in providing a basic background for English teachers and teachers throughout the educational institutions, developing good strategies and introducing learners to the correct writing skills patterns. Because writing seems to be difficult for English as Foreign Language/ English as Second Language (EFL/ESL) learners, on the other hand, it is crucial in all four language skills, and over the past few decades have witnessed the rapid emergence of some theories and new methods to solve the above problems. Many strategies and different skills have been born in few years. Their focus is on how to effectively teach and develop writing skills. Many studies have pointed out that this phenomenon still exists, and learners of language still fail to get the entire purpose of writing (Mahnam \& Nejadansari, 2012).

The teaching learning process is based on luminous thinking that is broadly used in distinctive educational fields. The students who want to learn a certain language require to learn a concept that tells how to absorb and then process thoughts and information variants in environment to the human brain, but interconnects by generating relational clips (Al-Jarf, 2011). This concept is commonly known as cohesion. It normally comprises of a central theme, sense, image or idea, and the interrelated thoughts are made by making branches from the crucial object but connected by relationship clips. The resulting thoughts are linked together and shape a layered graph created on the user's 
thoughts. A teaching technique commonly known as mind mapping technique also works to link the thoughts using certain procedural steps. A detailed description of the distinctive purposes was used today can be achieved by mind maps. Thus, mind maps consider as thought of as an active source for generating many ideas, and each idea creates new branches to increase the variety of achievable different associations (Cameron, 2001). Recall that language is a tool of teacher that enables them to initiate or assemble various words associated with a single topic, idea or topic. Traditionally, mind maps are an organized hierarchy of information and categories of information. But in essence, mind maps contain hierarchies and connections that come from free-flowing, still coherent and organized central images. The primary subtopic or subcategory associated with the central topic is connected by a branch from the central entity (Buzan, 2006).

From above, it is evident that Teaching od English as a Foreign Language requires a transition from traditional to innovative teaching techniques (like mind mapping technique) to meet the goals. Furthermore, writing skills of the students require special attention of the teachers. Hence, the purpose of this study was to highlight the effectiveness of mind mapping technique for the teaching of cohesion and coherence in composition writing.

\section{Objectives of the Study}

Following were the objectives of the study.

1. To measure the effectiveness of instructions based on mind maps and traditional teaching techniques to teach cohesion and coherence in composition writing.

2. To investigate the impact of gender on students' cohesion and coherence in composition writing when instructed through mind mapping technique.

\section{Hypotheses of the Study}

$\mathbf{H}_{\mathbf{0}}$ 1: There is no significant difference in the average scores of cohesiveness and coherence in students' composition writing based on mind mapping technique and traditional teaching technique.

$\mathbf{H}_{0}$ 2: There is no significant difference in the average scores of male and female students in the cohesiveness and coherence of composition writing. 
$\mathbf{H}_{0}$ 3: There is no interaction effect of treatment and gender on achievement of students in the cohesiveness and coherence of composition writing.

\section{Review of Related Literature}

\section{Writing}

Gelb and Gelb (1962) stated that writing is a method that is distinctly linked to human interaction through traditionally distinguishable symbols. Maybe writing begins with how individuals begin to see how to use a detectable password to convey their ideas and beliefs. They comprehended also these symbols need not only to understand but must also be attributed to other individuals thus establishing the specific communication procedure. Writing is considered a dialogue among authors and readers because it is studied as a way to learn and develop a person's reaction to a particular event, analysis or environment. In addition, John Lagan enhanced that writing is actually like diving and typing and like all other skills, writing can be learned and mastered. Therefore, for everyone, as a complex but indispensable process, practical writing is a very urgent need, and the ability to write well and constant is considered important.

\section{Composition Writing}

The term "composition" comes from 'components', meaning 'put together' (Gelb and Gelb, 1962). Therefore, the word composition is still close to this meaning, because many writing classes are also called combination classes; in addition, the symbols that write music symbols are also called composition. In addition to the importance of this composition, the word is also expended in the art field, because conceptual painting is often considered to be a stimulating work. In brief, a mixture of the components is referred to as a composition.

\section{Teaching Writing}

Hay (2007) explained that the purpose of writing teaching to EFL learners includes strengthening, language improvement and style and last writing skills but not the least. Rare students acquire language through verbal communication, but through strengthening many pupils can learn by visually reading the textbook. Language progress looks to be a constant procedure of English learning by following writing. Several pupils have an excellent learning style and they can quickly master language proficiencies by simply viewing and listening to the content being studied in the classrooms. Moreover, writing is an essential skill so 
it is very vital in language learning special for learning English. The time to write essays, letters, reports and advertisements has increased, so students must understand in what way to learn skills of writing distant languages.

\section{Good Writing}

A suitable writing is considered a kind of writing that perfectly fulfills the fundamentals of writing. Cameron (2001) stated that content, method, mechanism and style are some important components in good writing. Some of the important features of good writing are given below:

\section{Content}

The key points must be taken in writing so that careful readers can master the purposefulness of written assignment.

\section{Form}

It is related to the organization of the content. Authors should have an effective relationship between shared ideas so that readers can easily understand the connections between ideas shared in writing.

\section{Grammar} patterns.

Writing needs to keep on grammatical rules, forms, and synthetic

\section{Style}

The choice of structure besides vocabulary points provides a precise way for writing. It includes the author's actual visualization and the reader's accuracy.

\section{Mechanics}

Finally, for improved writing, you must ensure suitable spelling, punctuation, neat and clean writing.

\section{Writing Process}

The four parts of the writing process are:

1. Pre-writing contains four methods that help develop topics and develop words connected to these topics. These methods are questionable, free to write, create lists and make worn outlines.

2. It includes further considerations and information that did not appear during the writing process. This means rewriting the already written content to make it more powerful than the previous draft. 
3. It consists of three phases, namely modifying the content, modifying the sentence and editing.

4. This is the final stage in which the author writes an article by removing errors such as grammar, punctuation, and spelling.

\section{The Mind Mapping Technique}

The term 'mind mapping' was first used by Buzan (1993) who describes it as an instructional strategy where the learner "places supraordinate concepts on paper and subsequently links sub-ordinate concepts as appropriate" (p.59). According to Buzan and Buzan (1994), mind maps attempt, visually and graphically, to portray a relationship of ideas or concepts. Mind maps go under a variety of names. They are known as concept maps, semantic mapping, knowledge mapping, think-links, graphic organizers or cognitive maps (Svantesson, 1989). Mind mapping is creative note-taking method, which eases us to remember much information (De Porter, Readon, and Nourie, 1999). Trianto (2009) pointed out that mind maps are graphical representations in which a single idea is related to many other ideas or thoughts. It uses color symbols and pictures to help students not only study in a pleasant and good way but also help the students to use their brains to encourage their beliefs in a method that masters' vocabulary knowledge.

The mind mapping is a way to take notes and ensure that ideas are preserved for long periods of time. In addition, if they use color pictures and symbols, mind mapping is the best, so the production of art involves in it (DePorter, Readon, \& Nourie, 1999). According to Buzan (2003), the teachers use mind mappings technique to display not only facts, but also the overall picture of the concepts that describe the importance of their different parts. In addition, it can help students to connect with ideas that are relevant to a particular concept, otherwise these concepts may not be realized. This technique can be used to explore almost any concept, including descriptive articles and narrative works, as well as easy vocabulary knowledge. It can also help pupils to deliberate their thoughts in group work. This technique supports students to build relationships between thoughts and encourage gathering these thoughts to continue to discover new ideas.

\section{Research Methodology}

To measure the effectiveness of instructions based on mind mapping technique for the teaching of composition writing the researchers applied an experiment as it is an easy research technique to find the effectiveness of pedagogical techniques and methods. 
Furthermore, the researchers applied pre test post test control group design for this study. This research design allowed the researchers to select the participants using random sampling technique. According to Gay (2009), applying random sampling the best way control the extraneous variables. Hence, this design suited the current study.

All tenth grade learners are cogitated to be available to the study at Wah Cantt. Federal Government Public High School for boys and Federal Government Girls High School were purposively chosen to join the study. A random sample of 60 students (30 boys and 30 girls) was selected from these schools. The two groups (control group and experimental group) included 30 students (15 boys and 15 girls). A selfdeveloped Subject Achievement Test (SAT) was used to collect the data. It was an essay type test to measure the cohesions and coherence in composition writing. The same test was applied as pre and post tests to gather information from the students. The validity of the said test was ensued by experts while for reliability the said test was handed over to three experts for marking to ensure consistency between the evaluators.

\section{Procedures of the Study}

As the design of this study suggests, the control group (consisted of 15 boys and 15 girls) were treated using traditional teaching techniques whereas the experimental group accepted instructions based on mind mapping techniques. A week before the treatment process Student Achievement Test (SAT) was administered to students in both control and experimental groups to collect data before the start of experiment. The treatment period took for four weeks and there are 40 minutes of instruction per day per group. The guidance is provided through two teachers with the similar qualifications (Master of Arts in English / Master of Education (MA / M.ED)) and teaching experience of school (nearly five years). The teachers were informed to the whole purposefulness of the study before the start of the treatment. The researcher gave a complete briefing on the different strategies, aspects and types of composition writing and provided lesson plans related to traditional teaching technique and mind mapping technique. This update is added by a map on the basis of composition writing. During the treatment period, ten essay writing themes were selected for teaching. The same Student Achievement Test (SAT) which was used as pre test was administered after inputting the treatments to collect post test scores. 


\section{Results}

Descriptive Statistics

This segment gives descriptive analysis of data.

Table 1

Descriptive statistics: Pretest and posttest scores

\begin{tabular}{llllll}
\hline Scores & N & Mean & SD & Skewness & Kurtosis \\
\hline Pretest scores Experimental Group & 30 & 5.78 & 1.25 & -.361 & .194 \\
Pretest scores Controlled Group & 30 & 5.90 & 1.51 & -.131 & -.686 \\
Posttest scores Experimental Group & 30 & 6.95 & 1.22 & .158 & -.987 \\
Posttest scores Controlled Group & 30 & 5.61 & 1.35 & .157 & -.075 \\
\hline
\end{tabular}

Table 1 shows the scores of students' Pre-subject achievement test (PreSAT) in the experimental group (EG) and Controlled Group (CG) were tested, it was understood that the mean score of CG was 5.90 and EG was 5.78. It was seen that there was a difference of 0.12 between the mean scores of the said groups in terms of their pretest results. Table 1 also depicted Post-SAT scores analysis. It was understood that the average score of CG was 5.61, EG was 6.95, the average score of students in the experimental group was 1.17 , and the average score of students in CG was 0.29. Hence the descriptive statistics results favored the application of mind mapping technique. As the values of skewness and kurtosis lied between- 2 to +2 , hence, the normality of data was also evident.

\section{Inferential Statistics}

This section includes an analysis of the three null hypotheses previously specified. To test the null hypothesis, an analysis of variance (ANOVA) and an independent sample $t$ test were used with a significance level of 0.05. However, before testing the null hypothesis, the t-test was to check for any significant mean difference between the control group and the experimental group before the experiment.

Table 2

Independent sample t-test: pretest scores of SAT

\begin{tabular}{llllll}
\hline Groups & Mean & Standard Deviation & $t$ & $d f$ & $p$ \\
\hline Experimental & 5.78 & 1.25 & -.341 & 58 & .734 \\
Control & 5.90 & 1.51 & & & \\
\hline
\end{tabular}


Table 2 displays that there was no significant difference in the pretest scores of the student's academic scores in the control group (Mean= 5.90, Standard Deviation=1.51) and the experimental group (Mean= 5.78, Standard Deviation $=1.51$ ), as $t(58)=-.341, \mathrm{p}=0.734>0.05$. Therefore, in terms of Pre-SAT scores students were statistically equal.

Table 3

Independent sample t-test: Posttest scores of SAT in terms of groups

\begin{tabular}{llllll}
\hline Groups & Mean & Standard Deviation & $t$ & $d f$ & $p$ \\
\hline Experimental & 6.95 & 1.22 & 4.045 & 58 & 0.000 \\
Control & 5.61 & 1.35 & & & \\
\hline
\end{tabular}

Table 3 shows that there was a significant mean difference in the posttest scores for the subject scores of the control and experimental groups, such as $t(58)=4.045, \mathrm{p}=0.000$. It revealed that the students in the experimental group (Mean $=6.95$, Standard Deviation=1.22) performed well in the post-SAT scores with the control group (Mean= 5.61, Standard Deviation=1.35).

Table 4

Independent Sample t-test: In terms of Gender Post-test scores of SAT

\begin{tabular}{llllll}
\hline Gender & Mean & Standard Deviation & $t$ & $d f$ & $p$ \\
\hline Boys & 5.89 & 1.15 & -2.114 & 58 & .039 \\
Girls & 6.66 & 1.62 & & & \\
\hline
\end{tabular}

Table 4 shows that there was a significant mean difference in the student's academic scores and the post-test scores of boys and girls $t(58)$ $=-2.114, p=0.039$. The results of post SAT showed that the boys (Mean $=5.89$, Standard Deviation=1.15) were not better as compare to the girls $($ Mean $=6.66$, Standard Deviation=1.62).

Table 5

ANOVA: Effect of communication between gender difference and treatments

\begin{tabular}{llll}
\hline Source & $d f$ & $F$ & $p$ \\
\hline Group & 1 & 18.734 & .000 \\
Gender & 1 & 6.092 & .017 \\
Group*Gender & 1 & 4.305 & .053 \\
Error & 56 & & \\
\hline
\end{tabular}

The results of Table 5 show that the interaction between gender differences and treatment has no significant effect on the student's academic performance $\mathrm{F}(1,56)=4.305, \mathrm{p}=0.053>0.05$. 


\section{Discussions and Conclusions}

The major objective of the research study was to compare the effectiveness of instructions based on mind-mapping and traditional teaching technique to teach in relations of cohesion and coherence in composition writing on tenth grade students' achievement. The results of the study reflected that the students taught through mind mapping technique performed better as compare to the students taught through traditional technique. The results of the study are strengthened by the results of the studies like Trianto (2009), Buzan (1993) and De Porter, et al. (1999). Furthermore, Nebojsa et al. (2011) pointed out that the mind mapping technique is a powerful graphical tool which can be used to strengthen the minds of students to comprehend things easily. Being natural to the students, this technique can easily be adopted by the academicians. In addition, Harkirat and Makarimi-Kasim (2011) consider mind mapping an excellent tool to recapitulate the previous information. This enables the students to use the prior knowledge to construct new ideas. Liu et al. (2014) presented a meta-analysis on the effectiveness of mind mapping technique. They disclosed that this technique improved students learning all fields of education including science, arts and humanities. They also focused that a number of studies on conducted on language learning proved mind mapping an excellent teaching technique. Hence, it was concluded that traditional and mindmapping teaching technique (Grammar Translation Technique) to teach in terms of cohesion and coherence in composition writing.

Second objective of the study occurred to check the effect of gender on achievement of learners in relationships of cohesion and coherence in essay writing. The results reflected that the female pupils achieved well as relate to the male pupils. Latest researches revealed the same results (Akpinar, Yildiz, \& Ergen, 2009; Anwer, Iqbal \& Harrison, 2012; Dhindsa \& Chung, 2003; Greenfield, 1996). However, a few studies exposed contradictory results in favour of male students (Denessen, Vos, Hasselman \& Louws, 2015; Weinburgh, 1995). It is evident that the earlier studies revealed dissimilarities which might be due to geographical variances. So it was concluded that the female students were better in terms of using mind mapping technique for composition writing.

\section{Recommendations}

The results of this study insist that mind mapping technology plays vital role in the greatest level of achievement in learners. However, this 
can be achieved when learners are able to establish a connection between new concepts and concepts acquired in the past. Therefore, teachers may effort to stimulate the students' previous knowledge to promote a focused learning procedure.

Textbook authors, teachers and course developers may deliberate the status of mind mapping technology in Teaching of English as a Foreign Language. In addition, the school administration or the Ministry of Education may organize training and seminars related to mind mapping technique for teachers to facilitate teachers to improve their interpersonal and interpersonal skills. School management may play an important role in motivation of teachers to participate in such courses.

Curriculum designers may also use mind mapping technique to prepare teaching supplements related to different topics, especially teaching English and other subjects.

Teachers may deliberate the positive results of mind mapping technique when designing a student's teaching strategy. Therefore, guidelines of teacher may contain new methods to install the skills in dissimilar themes and subjects to increase student accomplishment. 


\section{References}

Akpinar, E., Yildiz. E., Tatar, N., \& Ergen, O. (2009). Students' attitudes toward science and technology: An investigation of gender, grade level, and academic achievement. Procedia Social and Behavioral Sciences, 1, 2804-2808.

Al-Jarf, R. (2011). Teaching Spelling Skills with a Mind-mapping Software. Asian EFL Journal Professional Teaching Articles. 53, 416.

Anwer, M., Iqbal, H. M., \& Harrison, C. (2012). Students' Attitude towards Science: A Case of Pakistan. Pakistan Journal of Social and Clinical Psychology, 10 (1), 3-9.

BouJaoude, S. B. (1992). The relationship between students' learning strategies and the change in their misunderstandings during a high school chemistry course. Journal of Research in Science Teaching, 29, 687-699.

Buzan, T. (1993). The Mind Map Book. London: BBC Books.

Buzan, T. (2003). Mind-maps for Kids. London: Harper Thorsons.

Buzan, T. (2006). Mind Map. Jakarta: Gramedia Pustaka Utama.

Buzan, T. and Buzan, B. (1994). The mind map book: How to use radiant thinking to maximize your brains untapped potential. Dutton.

Byrne, D. (1997). An overview (and underview) of research and theory within the attraction paradigm. Journal of Social and Personal Relationships, 14(3), 417-431.

Cameron, L. (2001). Teaching Languages to the Young Learners. UK: Cambridge University Press.

Cavallo, A. M. L. (1996). Meaningful learning, reasoning ability, and students' understanding and problem solving of topics in genetics. Journal of Research in Science Teaching, 33, 625-656.

Costa, N., Marques, L. and Kempa, R. (2000). Science teachers' awareness of findings from educational research. Chemistry Education: Research and Practice in Europe, 1(1), 31-36. 
Denessen, E., Vos, N., Hasselman, F., and Louws, M. (2015). The Relationship between Primary School Teacher and Student Attitudes towards Science and Technology. Education Research International.

DePorter, B. Reardon, M. \& Nourie S. S. (1999). Quantum Teaching: Orchestrating Student Success. Allyn and Bacon.

Dhindsa, H. S., \& Chung, G. (2003). Attitude and achievement of Bruneian science students. International Journal of Science Education, 25(8), 907-922.

Gay, L. R. (2009). Educational Research. Islamabad: National Book Foundation.

Gelb, A. \& Gelb, B. (1962). O'Neill. London: Jonathan Cape.

Greenfield, T. A. (1996). Gender, ethnicity, science achievement, and attitudes. Journal of Research in Science Teaching, 33 (8), 901-933.

Harkirat, S. D., Makarimi-Kasim, O. R. A. (2011). Constructivist-Visual Mind Map Teaching Approach and the Quality of Students' Cognitive Structures. Scientific Education Technology, 20, 186-200.

Harmer, J. (2001). The Practice of English Language Teaching. England: Longman.

Hay, D. B. (2007). Using concept maps to measure deep, surface and non-learning outcomes. Studies in Higher Education, 32( 1), 39-57.

Liu, Y. Zhao, G., Ma, G. \& Bo, Y. (2014). The Effect of Mind Mapping on Teaching and Learning: A Meta-Analysis. Standard Journal of Education and Essay, 2(1), 17-31.

Mahnam, L., \& Nejadansari, D. (2012). The Effects of Different PreWriting Strategies on Iranian EFL Writing Achievement. International Education Studies, 5(1), 154-160.

Nebojsa, S., Carisa, B., Milos, P., Veljko, A. (2011). The evaluation of using mind maps in teaching. TTEM- Technics Technologies Education Management, 6(2), 337.

Novak, J. D. (2002). Concept mapping: A useful tool for science education. Journal for Research in Science Teaching, 27, 937-950.

Svantesson, I. (1989). Mind mapping \& memory: Powerful techniques to help you make better use of your brain. London: Kogan Page. 
Taber, K.S. (2001). Constructing chemical concepts in the classroom: Using research to inform practice. Chemistry Education: Research and Practice in Europe, 2(1), 43-51.

Trianto. (2009). Design Model Learning Innovative-Progressive. Jakarta: Kencana Prenada Media Group.

Weinburgh, M. (1995). Gender differences in student attitudes toward science: A meta-analysis of literature from 1970 to 1991. Journal of Research in Science Teaching, 32 (4), 387-398.

Citation of this Article:

Shaheen, M. N. K., Shah, N. H., \& Naqeeb, H. (2020). Does mind mapping technique improve cohesion and coherence in composition writing? An experimental study. Pakistan Journal of Education, 37 (2), $31-45$. 
